\title{
Modelo de gestão municipal baseado na utilização estratégica de recursos da tecnologia da informação para a gestão governamental: formatação do modelo e avaliação em um município*
}

\author{
Leonardo de Oliveira Leite** \\ Denis Alcides Rezende***
}

Sumário: 1. Introdução; 2. Fundamentação teórica; 3. Modelo proposto para a gestão governamental; 4. Metodologia da pesquisa; 5. Proposta e avaliação do modelo para a gestão governamental; 6. Conclusão.

Summary: 1. Introduction; 2. Theoretical framework; 3. Proposed government management model; 4. Research method; 5 Proposal and assessment of the public management model; 6 . Conclusion.

Palavras-chave: sistemas de informações estratégicas; gestão pública municipal; group decision support system.

KEY WORDs: strategic information systems; municipal public management; group decision support system.

São desafios constantes da gestão efetiva dos municípios a estruturação e disponibilização de informações confiáveis, oportunas e personalizadas para apoiar as

\footnotetext{
* Artigo recebido em dez. 2008 e aceito em out. 2009.

** Mestre e doutorando em gestão urbana pela Pontifícia Universidade Católica do Paraná (PUC-PR) - Programa de Mestrado e Doutorado em Gestão Urbana. Endereço: Serviço Federal de Processamento de Dados, Regional Curitiba, CTA - Rua Carlos Pioli, 133 - Centro Cívico — CEP 80520-170, Curitiba, PR, Brasil. E-mail: leonardo.leite@serpro.gov.br.

**** Pós-doutor em administração pela Universidade de São Paulo. Professor e pesquisador da PUC-PR — Programa de Mestrado e Doutorado em Gestão Urbana e Programa de Pós-Graduação em Administração. Professor da FAE Business School no curso de graduação em administração. Endereço: Rua Imaculada Conceição, 1155, Parque Tecnológico, bloco 3 - Prado Velho - CEP 80215-901, Curitiba, PR, Brasil. E-mail: dar@denisalcidesrezende.com.br.
} 
decisões da administração pública municipal e para elaborar e controlar o planejamento estratégico municipal alinhado aos anseios dos cidadãos. A adaptação de modelos de gestão da iniciativa privada para o ambiente público é uma alternativa para enfrentar esses desafios. Este artigo propõe e avalia um modelo para a gestão governamental. O modelo é baseado na utilização estratégica da tecnologia da informação, que proporcione ao gestor público monitoração e controle da execução estratégica, informações executivas para a tomada de decisão, gestão dos relacionamentos com os cidadãos e o domínio sobre os processos da gestão municipal. A metodologia da pesquisa enfatizou o estudo de caso no município de Curitiba, utilizando um protocolo de pesquisa elaborado a partir da pesquisa bibliográfica exploratória. A seguir, são analisados diferenças, similaridades e resultados da aplicação de elementos que compõem o modelo proposto no município estudado. A conclusão evidencia que a utilização e adaptação do modelo proposto nas gestões municipais podem contribuir significativamente na evolução de seus modelos de gestão.

Municipal management based on the strategic use of information technology resources for government management: formatting and assessing the model in a city

There are challenges in the effective management of municipalities, the structuring and provision of reliable, timely and customized information, to support the decisions of the municipal government and to prepare and monitor the municipal strategic planning aligned with the citizens requirements. The adaptation of management models and concepts from the private sector to the public environment is one alternative for facing theses challenges. This article proposes and evaluates a government management model based on the strategic use of information technology, so as to offer to the public administrator monitoring and control of strategic implementation, information for executive decision-making, management of relationships with the public, and command over the municipal management processes. The research methodology emphasizes the case study in the city of Curitiba, using a research protocol prepared from an exploratory literature review. Differences, similarities and results of the application of the model in the city are analyzed. The conclusion shows that the use and adaptation of the proposed model in a municipal public administration can contribute significantly to the development of its management models.

\section{Introdução}

Alguns dos grandes desafios apresentados para a administração pública são: a gestão de sua estrutura, a busca pelas melhores informações em tempo ágil 
e a utilização dessas informações de forma efetiva e cônsone à estratégia do gestor público, alinhando-as, por fim, aos anseios dos cidadãos e a processos controlados e efetivos (Pfeiffer, 2000; Rezende, 2005). A preocupação com a gestão do desempenho é um ponto de convergência de diversas administrações públicas ao redor do mundo, como abordado em documento do governo português (Portugal, 2004:1).

\begin{abstract}
Na maioria dos países da União Europeia, a gestão do desempenho constitui o vetor essencial das reformas ligadas à gestão pública, salientando claramente a obtenção de resultados e fazendo intervir adequados conceitos e instrumentos de avaliação e de gestão do desempenho, que realçam a interdependência de três objetivos essenciais: melhoria da gestão e da prestação de serviços; aumento da responsabilização e do controle; obtenção de economias e redução de custos financeiros.
\end{abstract}

A administração pública municipal necessita aproveitar as novas possibilidades proporcionadas pelos avanços das tecnologias da informação e comunicação, pois é imprescindível que o gestor público municipal disponha de informações gerenciais e estratégicas adequadas, precisas e em tempo ágil, informações oportunas e personalizadas. As TICs viabilizam também a gestão dos processos internos e externos da administração pública municipal orientando o gestor público no conhecimento de seus cidadãos. É a integração desses elementos ao planejamento estratégico que possibilita a gestão do desempenho municipal (Graham, 1994; Cunha, 2000; Frey, 2004; Rezende e Castor, 2006).

Como uma alternativa na busca para a transposição desses desafios, surgiram, na administração pública, a aplicação de modelos de gestão da iniciativa privada e, também, a utilização de novas tecnologias na transformação e na modernização da gestão pública, inclusive municipal.

Este artigo propõe e avalia um modelo para a gestão governamental. Tal modelo é integrado por teorias de gestão municipal que, alinhado com recursos de sistemas e tecnologia da informação, proporcione ao gestor público informações oportunas e personalizadas para a tomada de decisão, análise do desempenho do governo municipal, gestão dos relacionamentos com os cidadãos e controle sobre os processos da administração. Para avaliar o referido modelo, foi analisado no município de Curitiba a sua existência, estruturação, diferenças e contribuições de elementos. 
O modelo proposto integra teorias de gestão municipal, alinhadas com recursos de sistemas e tecnologia da informação, proporcionando ao gestor público informações seguras para a tomada de decisão, análise do desempenho do governo municipal, aproximação do cidadão e controle sobre os processos da administração de forma integrada. Esse modelo de gestão pública é baseado em adaptações de modelos de gestão e tecnologias da informação, utilizados inicialmente na iniciativa privada. Contempla as relações entre pessoas, processos e estruturas de apoio envolvidas no uso efetivo de uma quantidade relativamente pequena de informação, mas informações executivas (informações oportunas e personalizadas) que permitam ao administrador público tomar decisões aprimoradas, tendo efetivamente o conhecimento e o controle sobre o desempenho de seu governo (Graham, 1994; Davenport e Prusak, 2000; Rezende, 2005).

\section{Fundamentação teórica}

São regatados de forma resumida os principais conceitos, oriundos da iniciativa privada, que foram a base para a formulação do modelo proposto.

\section{Business intelligence (BI)}

Os sistemas de apoio à decisão (SAD), entre eles o business intelligence (BI), têm um papel importante nos negócios e na sociedade atual, por possibilitarem a transformação de dados primários, em fatos e formas significativas ou, melhor dizendo, gerando informações executivas e inteligentes (Rezende, 2005).

Além de ser uma ferramenta, o business intelligence (BI) é um conceito que compreende a habilidade corporativa de explorar, analisar e utilizar inúmeras informações advindas de diversas bases, que serão determinantes no processo decisório. Esse tratamento da informação favorece a análise de grandes volumes de informações, bem como as relações de causa e efeito, transformando as entradas das bases de dados em informação útil e estratégica para a atividade empresarial (Barbieri, 2001; Both e Dill, 2005). 


\section{Balanced scorecard (BSC)}

O balanced scorecard (BSC) foi desenvolvido na década de 1990 por Robert Kaplan e David Norton, com o objetivo inicial de ser um sistema de mensuração de desempenho, mas que evoluiu para um sistema de gestão estratégica integrada (Herrero, 2005).

Para Herrero (2005:26), o BSC pode ser descrito em duas dimensões, para os colaboradores de uma organização:

—É um sistema de gestão que traduz a estratégia de uma empresa em objetivos, medidas, metas e iniciativas de fácil entendimento pelos participantes da organização.

- É uma ferramenta gerencial que permite capturar, descrever e transformar os ativos intangíveis de uma organização em valor para os stakeholders.

No BSC a estratégia da organização é traduzida em objetivos que permitem a avaliação da sua performance, tomando por referência quatro perspectivas de valor: perspectiva financeira; perspectiva de clientes; perspectiva de processos internos; e perspectiva de aprendizado e crescimento (Kaplan e Norton, 2004).

\section{Customer relationship management (CRM)}

Swift (2001:13) define o CRM como "um processo interativo que transforma informações sobre clientes em relacionamentos positivos com os mesmos". As empresas buscam identificar o cliente, conhecê-lo, diferenciar (avaliando as suas necessidades e exigências), interagir com o cliente (reavaliando suas necessidades) e personalizar esse relacionamento (Swift, 2001).

O CRM pressupõe o redesenho dos processos da empresa, com processos operacionais ágeis e com um modelo de relacionamento que gere valor em longo prazo para o cliente (Bretzke, 2000). Ainda segundo o autor, os dois pilares do CRM são: "um processo de trabalho orientado para o cliente, que permeia e é compartilhado por toda a empresa; e o uso intenso da informação do cliente, suportado pela informatização de vendas, marketing e serviços". 


\section{Business process management (BPM)}

Pode-se dizer que o BPM é uma metodologia e um conjunto de práticas de gestão baseado na gestão e inteligência de processos (Dutra, 2004; Grigori et al., 2004; Monteiro, 2004).

De acordo com a definição elaborada por Monteiro (2004), "o processo é representado como uma sequência ou árvore de unidades de trabalho mais elementares com os respectivos caminhos de execução e registros de informação, todos determinados pelas regras em vigor". É no conceito de workflow que o BPM encontra suas origens. Fluxos de trabalho que fornecem uma visão global de todo o processo, ou de partes dele, e ainda permite a redefinição dos processos da organização.

O BPM, contudo, alcança patamares ainda mais sofisticados. Além de automatizar e iconografar o fluxo de trabalho, também envolve uma integração completa, do começo ao fim, envolvendo tarefas humanas e operações automatizadas, gerando dados para as tarefas automatizadas, produzindo resultados para a definição de diretrizes a seguir e monitorando os processos em trâmite. Propicia ainda a flexibilização da alteração das regras de negócio, proporcionando simulações de diferentes ambientes e cenários (Grigori et al., 2004; Monteiro, 2004; Jeston e Nelis, 2006; LABP3, 2006).

\section{Group decision support system (GDSS)}

Um sistema de apoio a decisões em grupo, com a denominação em inglês de group decision support system (GDSS), é definido por Sprague e Watson (1991:312) como "um sistema computacional interativo que facilita a resolução de problemas não estruturados através de um grupo de pessoas responsáveis pela tomada de decisões trabalhando juntas".

Envolvendo hardware, software, pessoas e procedimentos para apoio às atividades de tomada de decisão "em grupo", o GDSS trata da recuperação (seleção dos dados), partilha (apresentação dos dados ao grupo) e uso de informações (procedimentos e técnicas para a resolução de problemas) (Sprague e Watson, 1991).

Conforme a duração da sessão de tomada de decisão e o grau de proximidade física dos membros do grupo, são mapeados quatro cenários para um GDSS, observados na figura 1 (Sprague e Watson, 1991). 


\section{Figura 1 \\ Os quatro cenários para um GDSS}

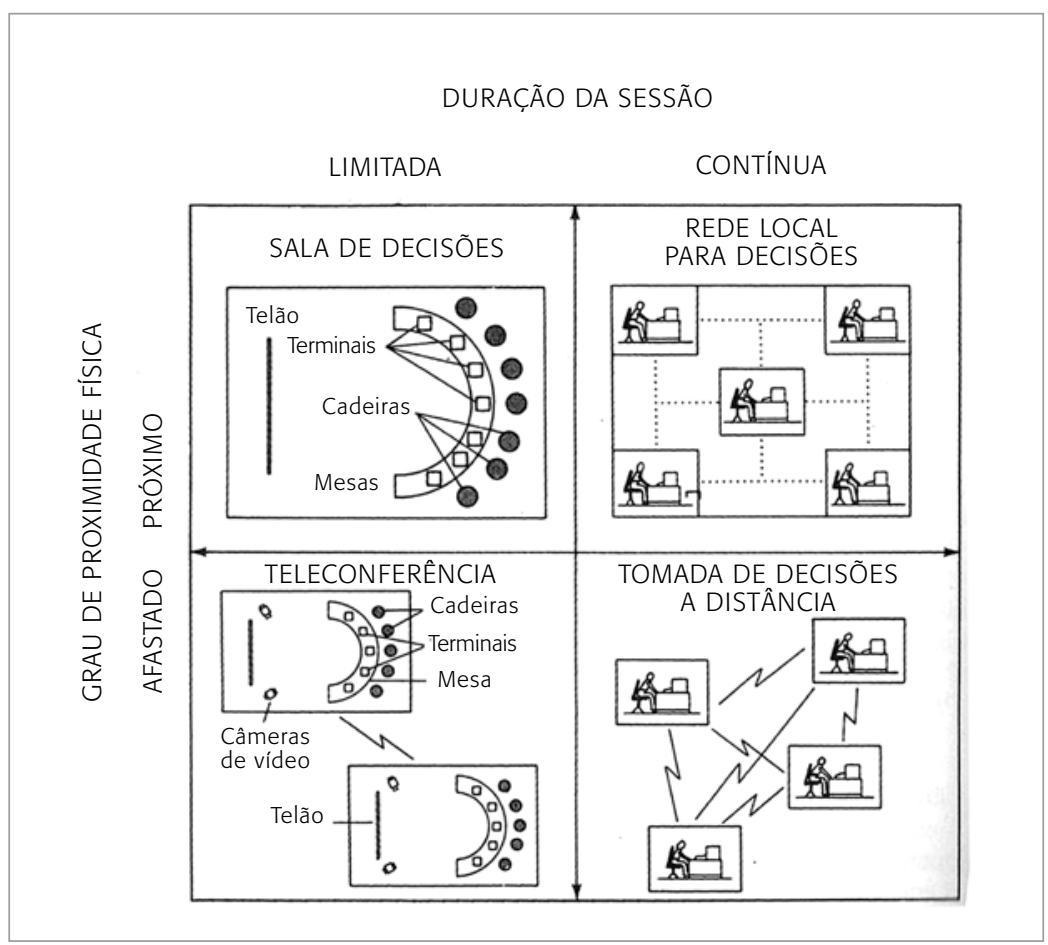

Fonte: Sprague e Watson (1991).

\section{Sala de decisões}

A organização pode destinar instalações especiais para a tomada de decisões em grupo, com os critérios do grau de proximidade física próximo e o tempo de duração da sessão limitado, que pode ser denominado sala de decisões (observar figura 1). O arranjo proposto por Sprague e Watson (1991) apresenta uma mesa em forma de ferradura, com computadores individuais para cada participante e voltada para telões que servirão para visualizar e analisar dados.

Na figura 2 pode ser visualizado o laboratório de GDSS da Lappeenranta University of Technology, seguindo conceitos expostos no parágrafo anterior. 


\section{Figura 2}

\section{Laboratório de GDSS localizado na Lappeenranta University of Technology}

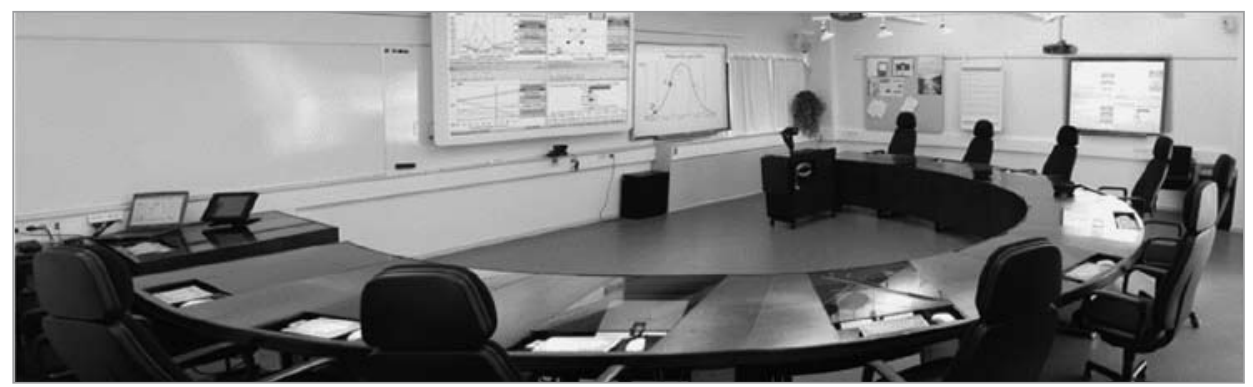

Fonte: Lappeenranta University of Technology (2007).

O ambiente e as ferramentas tecnológicas da sala de decisão são essenciais para o processo de tomada de decisões. A sala não pode ter ruídos externos e a iluminação e a ventilação devem ser adequadas, propiciando uma "atmosfera controlada" (Nunamaker et al., 1997).

O design da sala de decisão em formato de U mostra-se adequado para até 16 participantes. Existem outras configurações de sala de decisões para grupos maiores, com características e utilização distintas, como o Executive Decision Center da University of Arizona (figura 3), que comporta grupos de até 60 pessoas (Sprague e Watson, 1991; Nunamaker et al., 1997; University of Arizona, 2007).

\section{Figura 3}

Executive Decision Center localizado na University of Arizona

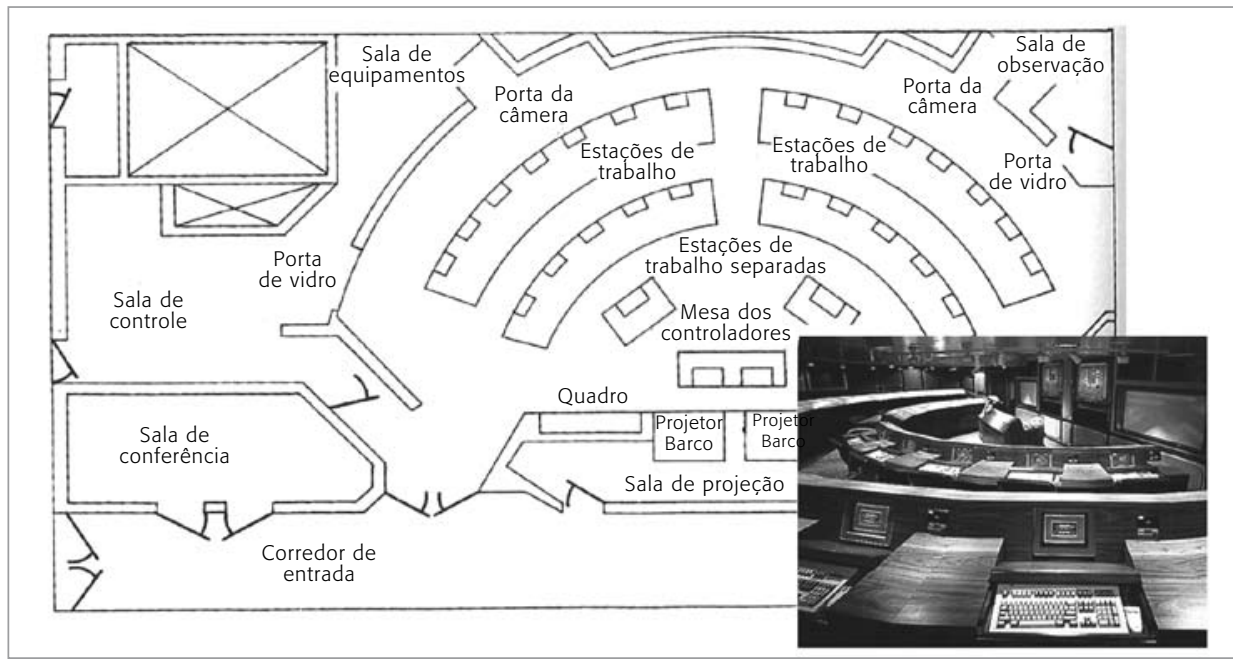

Fontes: Sprague e Watson (1991), University of Arizona (2007). 
O conjunto de ferramentas e/ou softwares disponíveis deve ser fácil de usar, interativo e preferencialmente de apresentação gráfica (Sprague e Watson, 1991).

\section{Modelo proposto para a gestão governamental}

O modelo em questão foi formatado a partir da integração de modelos de gestão e conceitos de mercado da iniciativa privada, ambos adaptados às particularidades da administração pública municipal (figura 4).

Essa proposição contempla ainda um ambiente decisório, modular, porém integrado, onde tem lugar o acompanhamento da execução estratégica (painel de bordo da estratégia), o apoio ao processo decisório e análises históricas (inteligência do negócio), o controle sobre os processos da administração (gestão dos processos internos) e a busca de aproximação entre prefeitura e cidadãos (gestão dos relacionamentos com os cidadãos).

Figura 4

Modelo proposto para a gestão da performance governamental

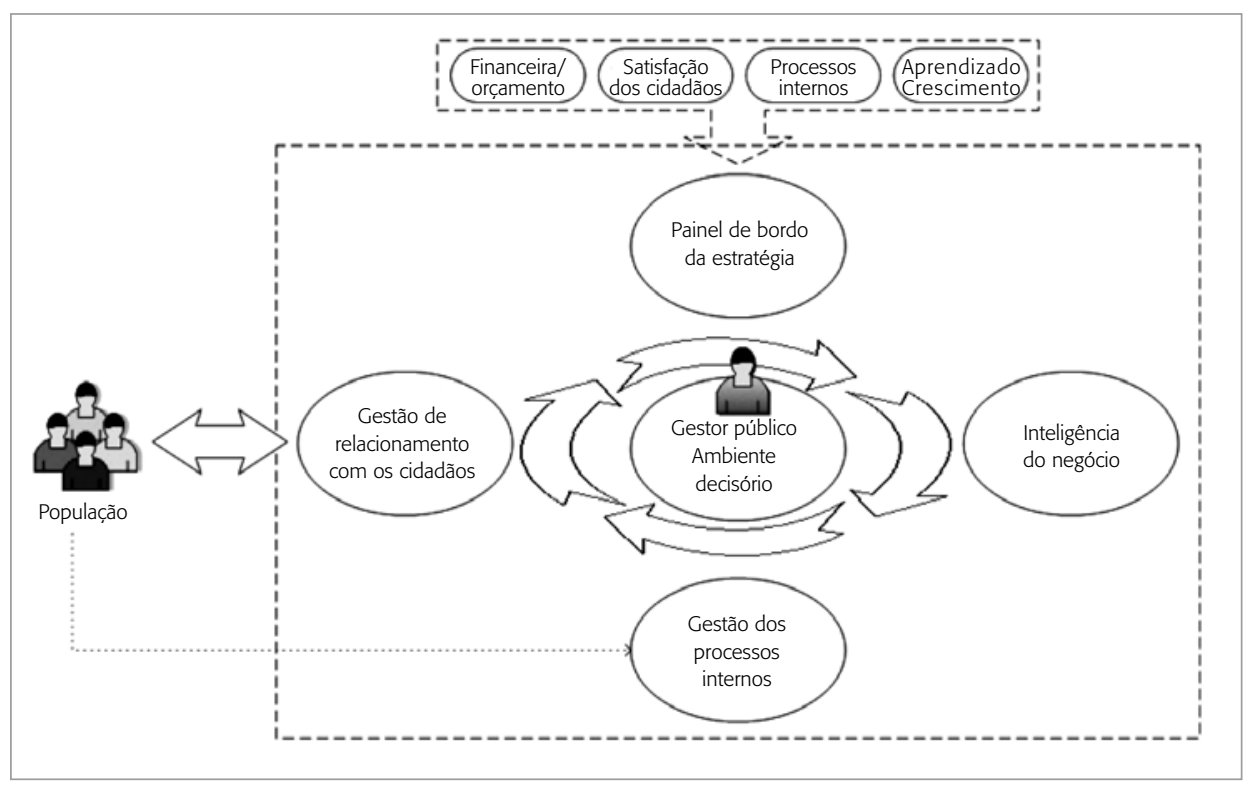

O painel de bordo da estratégia (baseado no balanced scorecard - BSC), trazendo os pressupostos do planejamento e alinhamento estratégico para o 
ambiente público, é a "espinha dorsal" do modelo proposto. Assim, o painel de bordo da estratégia representa o principal instrumento de gestão e controle do planejamento estratégico para o município ou prefeitura, explicitando os objetivos e permitindo o acompanhamento de sua execução.

Trabalhando de forma integrada ao painel de bordo da estratégia, o modelo proposto traz a gestão dos processos internos (adaptação do business process management - BPM), estruturando processos transversais, integrados e orientados para o cidadão, formulados para a execução do planejamento estratégico. Com a gestão dos processos internos é possível o mapeamento, monitoramento e correção de processos, alinhando-os ao planejamento estratégico e permitindo a alimentação automática de importantes indicadores do painel de bordo da estratégia.

A seta de ligação entre a gestão dos processos e a população (figura 4) representa a possibilidade de gerar uma nova forma de interação que permite aos cidadãos capacitados na tecnologia conhecer os processos da administração pública. Numa evolução desse cenário, é possível aos cidadãos, até mesmo, acompanhar online os processos, formular novos ou otimizar processos já existentes no município.

A gestão de relacionamento com os cidadãos (adaptação do customer relationship management, inclusive da denominação para citizen relationship management e do acrônimo para CzRM) tem a função de gerenciar uma parte dos relacionamentos dos cidadãos com a administração pública municipal, gerando informações que permitem ao gestor público conhecer suas expectativas, o nível de satisfação, as reclamações, as demandas e as características socioeconômicas e educacionais dos cidadãos de seu município. Além disso, esse conjunto de informações de relacionamentos com os cidadãos permite a evolução para um atendimento personalizado e de maior qualidade ao munícipe, impactando nos processos de toda a prefeitura. Funcionando, portanto, como uma espécie de "motor" da máquina da prefeitura, sinalizando as pendências para os diversos níveis hierárquicos e comunicando à população as possibilidades de atendimento e a atuação da prefeitura. Por outro lado, possibilita ao gestor público conhecer seu cidadão, entender seus anseios e sua satisfação em relação à execução do planejamento estratégico e ações da administração pública.

Integrando-se ao modelo a inteligência do negócio (o business intelligen$c e-\mathrm{BI}$ ) visa principalmente apoiar os processos decisórios da gestão municipal, proporcionando a maximização do uso dos recursos públicos, direcionando os esforços de acordo com os objetivos pretendidos e realizando-os. Com essa incorporação, todo o processo passa a ser orientado por informações coerentes (oportunas e personalizadas), ágeis, e dispostas de forma organizada 
de acordo com a necessidade dos gestores dos diversos órgãos do município e principalmente do prefeito.

O ambiente decisório (baseado no group decision support system GDSS) é onde convergem e visualiza-se a integração dos demais elementos desse modelo. $\mathrm{O}$ ambiente decisório tem por objetivo garantir à administração pública municipal uma visão integrada das ações e resultados, permitindo aos gestores municipais direcionar com o máximo de efetividade a execução do planejamento estratégico do município.

\section{Painel de bordo da estratégia (balanced scorecard - BSC)}

Condição indispensável para o funcionamento do painel de bordo da estratégia é a existência de um planejamento estratégico formal para o município ou administração pública. É nesse planejamento que se define uma série de variáveis que determinam onde a empresa, ou instituição municipal, quer chegar.

A base desse modelo de painel de bordo da estratégia para a administração pública municipal é uma adaptação do BSC para o setor público realizada por Niven (2005). Nela são consideradas as especificidades de uma administração pública orientada para resultados e para o cidadão.

A perspectiva dos clientes é substituída pela dos "cidadãos", englobando eleitores, contribuintes, usuários de bens e serviços públicos, a sociedade e o munícipe. Essa substituição é justificada pelo fato de o cidadão ser o referencial de toda a atividade de um governo.

Essa perspectiva apresenta dois importantes focos: o cidadão/cliente, relacionado aos produtos/serviços prestados e o cidadão/sociedade, relacionado à efetividade da administração pública (Ghelman, 2006). Como exemplos de alguns objetivos que podem estar na perspectiva dos cidadãos temos: a universalização da prestação dos serviços públicos; a satisfação das necessidades públicas; a participação da população na administração; e a aprovação da administração municipal pelos munícipes.

A perspectiva processos internos deve refletir os processos que são críticos para se elevar a chance de alcançar o sucesso para os cidadãos, oferecendo serviços públicos de qualidade e com excelência operacional. A ampliação dos universos populacionais a serem cobertos pelos programas sociais depende do aumento da eficiência, que por sua vez depende do aperfeiçoamento dos processos da administração pública. Um hospital público, normalmente, só ampliará seu atendimento se otimizar seus recursos (Ghelman, 2006).

A perspectiva aprendizado e crescimento envolve um corpo de funcionários motivados, com competências e ferramentas adequadas. Nessa perspectiva também está englobada a modernização administrativa. A gestão de 
pessoas na administração pública é um desafio, pois é complicada a distinção e premiação de um funcionário que desempenha com excelência suas funções de outro que não alcança o resultado esperado. Assim, são essenciais as ações de sensibilização, capacitação e valorização dos funcionários públicos.

As relações de causa e efeito entre as perspectivas são totalmente alteradas em relação ao BSC tradicional (figura 5), de modo que, um bom andamento na perspectiva financeira/orçamento, impacta positivamente na perspectiva aprendizado e crescimento, e essas duas perspectivas acarretam uma melhoria nos processos internos. Portanto, nota-se que essas perspectivas têm uma relação direta com a perspectiva cidadãos.

Figura 5

Comparação da estrutura de um mapa estratégico do BSC tradicional com a adaptação do BSC para a administração pública

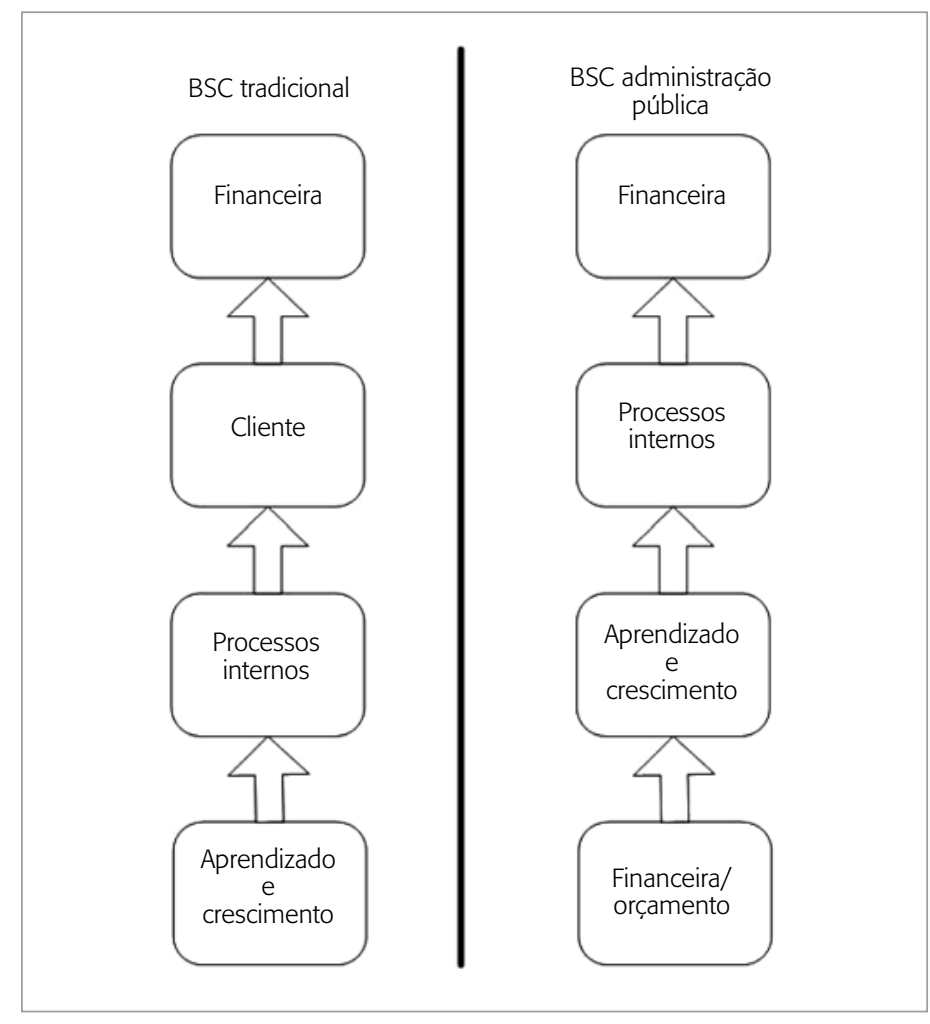

Se em uma administração pública, a perspectiva financeira/orçamento dá sustentação às demais perspectivas, uma ampliação da receita ou otimização 
da execução orçamentária permitirá o melhor funcionamento da administração. Com maior capacidade financeira, a administração pública tem mais capacidade para capacitar seus funcionários e aprimorar a gestão.

Para uma administração pública com funcionários capacitados que percebem a necessidade de racionalizar os recursos, orientados para o atendimento ao cidadão e para a melhoria da gestão, há um aumento da eficiência e da produtividade dos processos internos. Com processos mais eficientes pode-se ampliar e melhorar os serviços prestados resultando no aumento da satisfação dos cidadãos (Ghelman, 2006).

O papel da tecnologia da informação (TI), tanto para coletar as informações quanto para seu acompanhamento e monitoração é essencial nesse cenário. Na coleta de informações os sistemas de medição automáticos devem ser preferidos em detrimento dos manuais, com isso aproveitando e adequando os diferentes sistemas e fontes de dados já existentes, para a alimentação dinâmica do scorecard (Olve, Roy e Wetter, 2001).

A criação de medidas de desempenho inovadoras, principalmente aquelas relacionadas a objetivos sociais, representa uma das principais dificuldades dessa adaptação do BSC para a administração pública.

\section{Gestão de relacionamento com os cidadãos (citizen relationship management - CzRM)}

Esse modelo de gestão de relacionamento com os cidadãos aborda os relacionamentos utilizando as telecomunicações, mais especificamente a telefonia, além de uma plataforma tecnológica integrada para permitir um atendimento personalizado aos cidadãos e possibilitar ao gestor público conhecer as necessidades e anseios da população.

Não são abordadas nesse modelo outras formas de relacionamento entre poder público e cidadãos, como, por exemplo, os conselhos sociais. Também não são discutidas aqui questões de privacidade de informações.

Os conceitos e a estruturação do customer relationship management (CRM) da iniciativa privada são adaptados para o setor público municipal, inclusive a denominação para citizen relationship management, e o acrônimo para CzRM.

São os diversos sistemas de informação do município que produzem os dados de relacionamento entre a prefeitura e os cidadãos que, geralmente, ficam em plataformas diferenciadas e bases dispersas.

Em Curitiba, por exemplo, os sistemas que mais geram volume de dados são os atendimentos em postos de saúde, as infrações de trânsito, as solicitações de serviços e os cadastros de escolas municipais. Todos pertencentes a diferentes secretarias, com finalidades e especificidades fortemente diversas. 
O grande desafio da tecnologia da informação nesse cenário é integrar essas diversas bases de dados para que se relacionem e comuniquem de forma sintônica, gerando informações integradas e consolidadas para apoiar o processo de tomada de decisão dos gestores públicos.

Além disso, as tecnologias da informação também representam um papel determinante no estabelecimento de interação e comunicação com os cidadãos, sendo figuradas nesse panorama pela internet, pelos contact centers, quiosques de autoatendimento, entre outros.

\section{Estrutura}

O modelo de gestão de relacionamento com os cidadãos proposto apresenta três contact centers que interagem diretamente com o cidadão.

- Central 156: é um serviço de utilidade pública, já regulamentado pela Agência Nacional de Telecomunicações (Anatel) e destinado às administrações municipais. Diversos municípios brasileiros já implantaram o serviço 156 para atendimento a demandas da população. É essencialmente um contact center receptivo.

- Central de relacionamento: tem a responsabilidade de comunicar as ações da administração pública nas mais diversas áreas, bem como os projetos e serviços prestados. É um contact center ativo que realiza a divulgação e convites para eventos como inaugurações, campanhas e novos projetos da prefeitura, além de contatos direcionados aos participantes dos programas e cursos da prefeitura com o intuito de manter um cadastro constante para convite e divulgação de novos eventos.

- Central de pesquisas: é um contact center ativo que realiza pesquisas telefônicas junto aos usuários dos serviços da administração pública, realizando a avaliação dos projetos e programas disponibilizados para a população. Também pode realizar pesquisas de opinião pública para apoio à tomada de decisão, sobre temas polêmicos e a satisfação dos cidadãos em relação aos serviços públicos e à administração.

Os contact centers acima descritos alimentam suas próprias bases e também as de outros sistemas integrados. O cruzamento desses dados gera uma grande base de informações que podem ser transformadas em conhecimento sobre os cidadãos do município, suas principais necessidades e reivindicações.

Integrar as diferentes bases que compõem a plataforma tecnológica do município propicia um atendimento personalizado aos cidadãos, levantando rápida e eficientemente o histórico de relacionamento deste cidadão com a administração pública municipal (figura 6). 
Figura 6

Estrutura de gestão de relacionamento com os cidadãos do modelo proposto

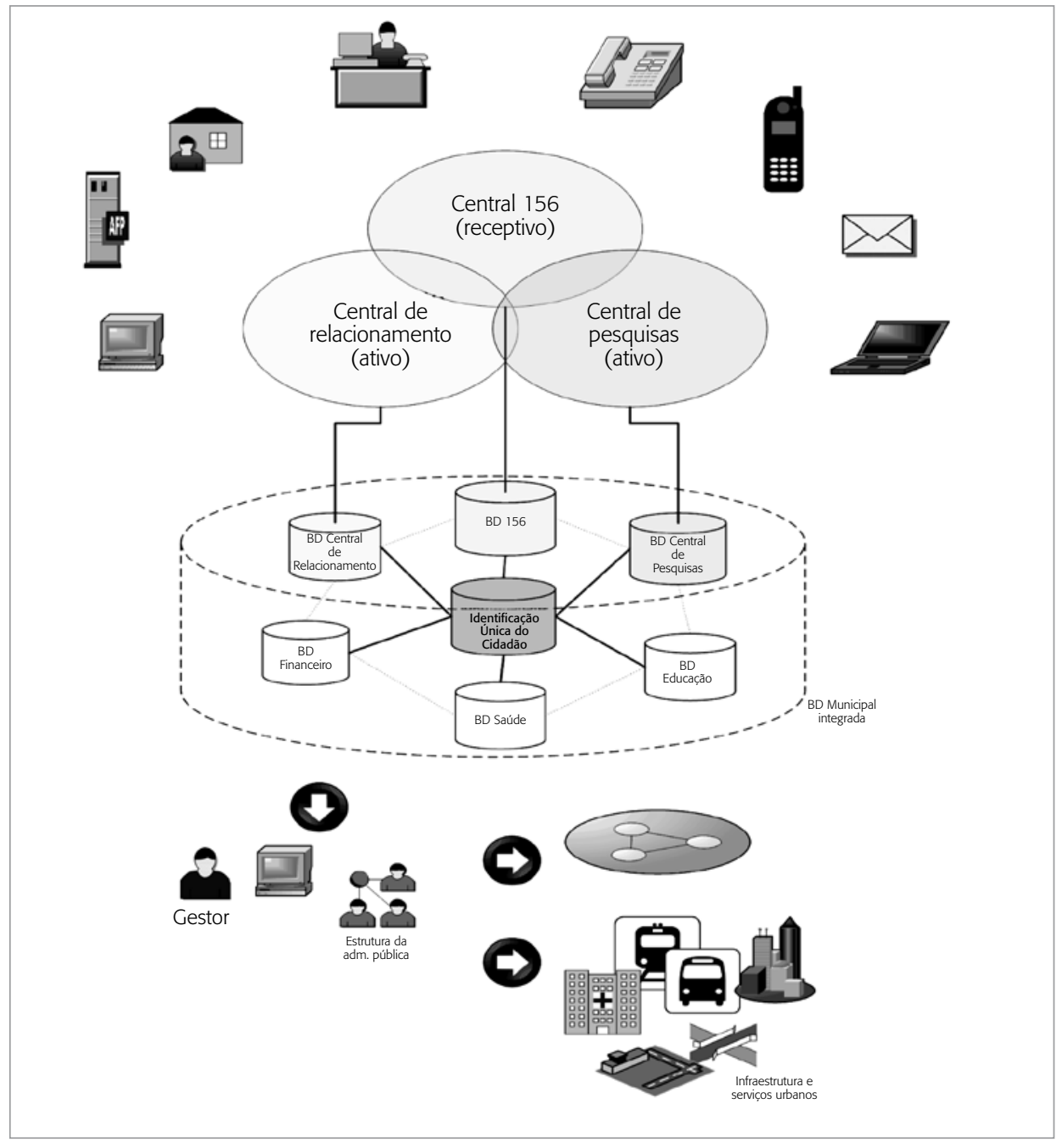

Uma das estratégias possíveis para a integração das diferentes bases de dados existentes no município é a geração de um grande data warehouse (armazém de dados), mas essa possibilidade não é muito atrativa quando são analisados os custos e o tempo de desenvolvimento de projetos desse tipo. Outra estratégia, mais próxima à realidade financeira das prefeituras e que pode proporcionar grandes benefícios ao sistema de informação muni- 
cipal como um todo, é a geração de uma base central de dados de "identificação única do cidadão", que possuirá dados cadastrais básicos de todos os cidadãos, visando à identificação unívoca de cada cidadão e possibilitando o relacionamento dessas informações cadastrais básicas do cidadão às suas informações nas demais bases de dados existentes na prefeitura.

Além disso, pode ser realizada a utilização de metadados padronizados para todos os sistemas de informação municipais que, em conjunto com a identificação única do cidadão, viabilizariam a implementação da comunicação e troca de informações entre os diferentes sistemas municipais.

\section{Gestão do relacionamento movimentando a máquina pública municipal}

Agindo como uma espécie de "motor" no processo de atendimento e de funcionamento da prefeitura, sinalizará as ações para os diversos níveis hierárquicos, e, por outro lado, comunicará à população suas possibilidades de atendimento, seus projetos e obras de melhoria na infraestrutura e nos serviços urbanos. Além disso, os gestores possuirão informações suficientes para avaliarem seus processos internos e os otimizarem buscando maior efetividade da máquina pública.

Dessa forma a gestão de relacionamento com os cidadãos movimentará a máquina pública municipal para o atendimento das demandas permitindo aos gestores públicos terem à sua disposição uma variedade de informações como: as demandas, as expectativas e os anseios até os níveis de satisfação e efetividade no atendimento das demandas solicitadas.

\section{Inteligência do negócio (business intelligence - BI)}

As soluções de inteligência do negócio (business intelligence) baseadas na geração de um grande data warehouse são normalmente caras e demoradas para o alcance de resultados práticos. Algumas organizações estão buscando alternativas sem passar pelo data warehouse, primeiro construindo os data marts (armazéns de dados) coordenados utilizando as mesmas dimensões em todo o modelo e garantindo a integridade corporativa. Com isso se consegue uma implantação de forma modular, conforme as possibilidades orçamentárias do momento, sem acarretar em retrabalho para uma solução corporativa, integrando-se esses diferentes módulos.

Ainda assim, essas soluções que adotam ferramentas online analytical processing (Olap), necessitam, primeiramente, de grandes projetos de extract, 
transform, load (ETL) com custos de aquisição, implantação e manutenção extremamente vultuosos, além dos elevados custos de armazenamento do grande volume de dados "redundantes".

Mas começam a surgir no mercado soluções que pretendem melhorar essa relação custo versus benefício, aproveitando os avanços tecnológicos nas áreas de processamento e armazenamento computacional, oferecendo uma solução de BI que não implique longos e dispendiosos projetos de data warehouse e de data mart ou as custosas ferramentas de Olap.

\section{Tecnologia}

Nesse modelo de business intelligence, a tecnologia utilizada propõe a quebra de alguns paradigmas de soluções de BI normalmente encontradas no mercado. Inicialmente é gerado um "script" carregando dados diretamente dos bancos de dados OLTP. Com o mecanismo denominado associative query logic (AQL) que, enquanto move os dados para um repositório não replica informações, mas associa registros utilizando ponteiros. Lendo assim apenas dados não duplicados e ponteiros são carregados utilizando o repositório na memória.

Quando é feita uma seleção, esta se propaga pelo banco de dados relacional gerado na memória. Ele já possui embutida e integrada à ferramenta ETL, que possibilita a limpeza e a carga dos dados. Funciona como um motor analítico, que pode ter ilimitadas dimensões e comprimir em até $80 \%$ os dados carregados. Finalmente, possui também as funcionalidades de relatórios similares às de ferramentas Olap, possibilitando a criação de dashboards, KPIs, gráficos e diversos outros formatos de relatórios (Qlikview, 2004, 2005).

\section{Estrutura}

O modelo estrutura uma solução de business intelligence viável para prefeituras no apoio ao seu processo decisório e de planejamento estratégico, com menores custos e tempo para atingir resultados concretos com o projeto.

A inteligência do negócio exposto neste modelo é estruturado por secretaria ou temática municipal, sendo que uma secretaria pode consultar dados de vários assuntos (como, por exemplo, saúde, educação, financeiro, obras...). No modelo, cada secretaria conta com sua estrutura própria de inteligência do negócio, consultando dados de assuntos dos quais determinada secretaria é responsável, podendo relacioná-los com outros bancos de dados referentes a assuntos pertinentes a outras secretarias. Então, em cada secretaria é criado o centro de 
informações estratégicas (nome dado para o ambiente onde seria realizada a operacionalização do $\mathrm{BI}$ ), diretamente ligado ao secretário responsável. Esse centro de informações estratégicas tem a missão principal de apoiar o processo decisório do secretário e auxiliá-lo na concepção e controle de seu planejamento estratégico setorial e no seu alinhamento e alcance do planejamento estratégico municipal, utilizando para isso o modelo proposto de inteligência do negócio, com a geração de cases conforme as demandas por informações do determinado gestor público.

Diretamente ligada ao prefeito (no gabinete do prefeito, por exemplo) ou ao gestor público que seja o principal responsável pelo planejamento e andamento da administração municipal (gestor público responsável) é criada a coordenação de informações estratégicas, a qual teria um papel similar aos dos centros de informações estratégicas, diferenciando-se por possuir uma visão mais abrangente e focada nas necessidades do prefeito (ou gestor municipal responsável).

\section{Figura 7}

Estrutura do modelo proposto de inteligência do negócio em uma prefeitura

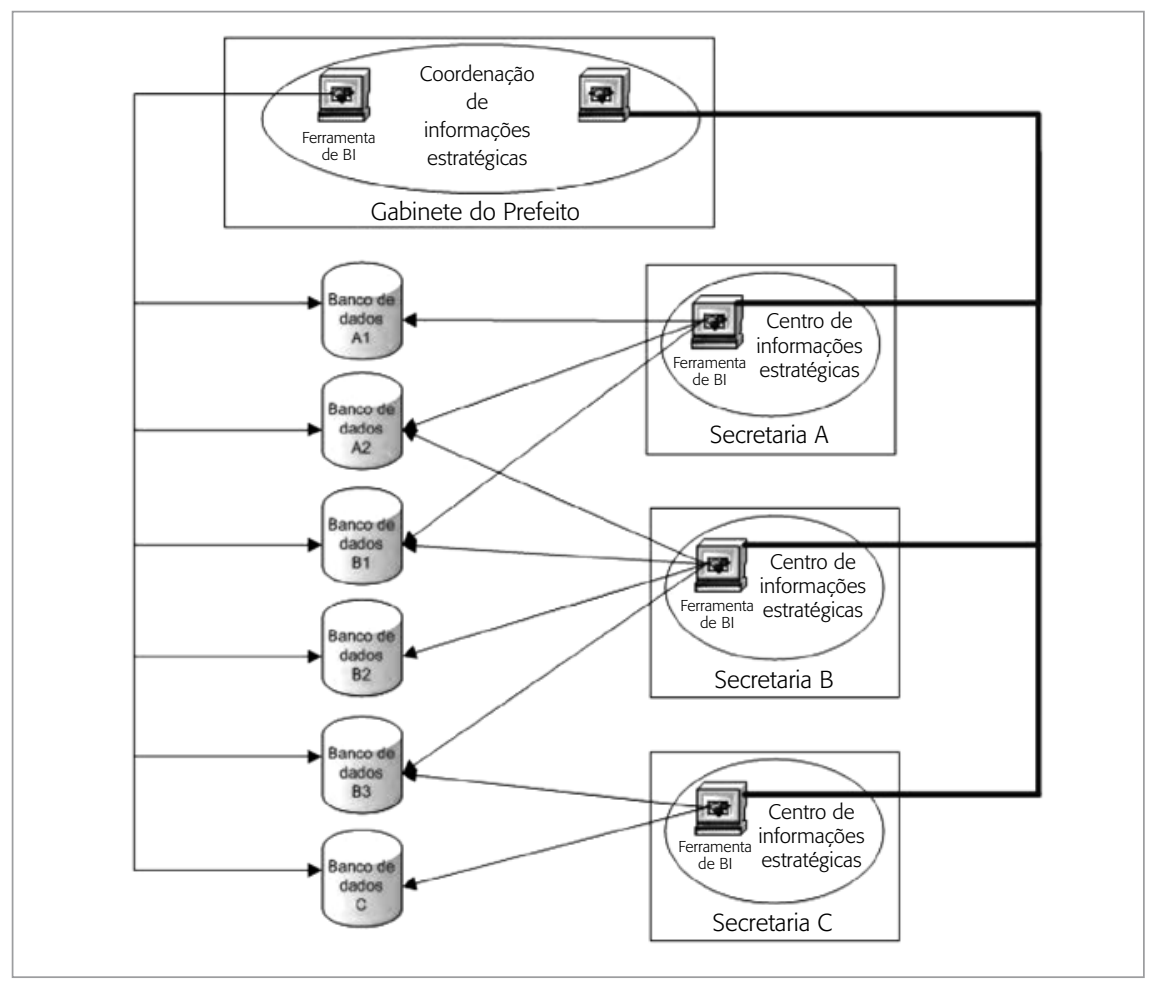


Essa coordenação trabalha principalmente com informações estratégicas e possui acesso para consulta a todos os cases formulados pelos demais centros de informações estratégicas. Mas essa coordenação trabalha de forma independente dos demais centros, criando suas próprias pesquisas, análises e relatórios, tendo como missão principal apoiar o processo decisório do prefeito (ou gestor público responsável) e a concepção e controle do planejamento estratégico municipal (figura 7).

Assim as diversas secretarias municipais, por meio de seus centros de informações estratégicas, podem formatar e utilizar o BI conforme as necessidades de informações dos gestores municipais, personalizando o sistema de apoio à tomada de decisões e acompanhamento do planejamento estratégico, mas sem esquecer da visão holística necessária para o prefeito (ou gestor público responsável).

\section{Pessoas e capacitações}

Os atores e as capacitações envolvidas no modelo de inteligência do negócio proposto são:

- prefeito e secretário municipal - atores que têm o poder da tomada de decisão e os principais "clientes" da solução de inteligência do negócio. O entendimento de sua visão e das informações necessárias para o processo decisório são essenciais;

$\checkmark$ analista de negócio - ator com conhecimentos do negócio, processos existentes e do planejamento estratégico no qual está inserido. Deve possuir contato direto com o prefeito ou secretário, conseguindo levantar as reais necessidades e desejos destes em relação à tomada de decisão e ao planejamento estratégico. Deve ser capacitado, pelo menos em nível básico, na ferramenta de BI e sendo desejável entender o modelo como um todo;

$\checkmark$ especialista em BI - ator com conhecimentos aprofundados na ferramenta e no modelo da solução de BI;

v administrador de banco de dados (DBA) ou administrador de dados (AD) — o primeiro é responsável pela tecnologia envolvendo os bancos de dados, o segundo é o responsável pelo seu modelo lógico. Em muitas organizações esses papéis são desempenhados pelas mesmas pessoas. No modelo proposto, o DBA deve prover o acesso aos bancos de dados e o AD tem o importante papel da explicitação dos modelos lógicos dos bancos de dados envolvidos. É desejável que o $\mathrm{AD}$ possua capacitação na ferramenta de $\mathrm{BI}$ e entenda o modelo como um todo podendo contribuir com os especialistas em BI e analistas de negócio. 
$\mathrm{O}$ analista de negócios é quem ajuda a definir, junto ao analista de BI, as necessidades de informações do prefeito/secretário. O analista de BI implementa o que foi definido pelo analista de negócios na ferramenta de BI, buscando aproveitar ao máximo todas as possibilidades e funcionalidades que a ferramenta de BI proporciona, contando com o suporte dos ADs e DBAs, conforme representado na figura 8.

\section{Figura 8}

\section{Pessoas e capacitações envolvidas no modelo de inteligência do negócio proposto}

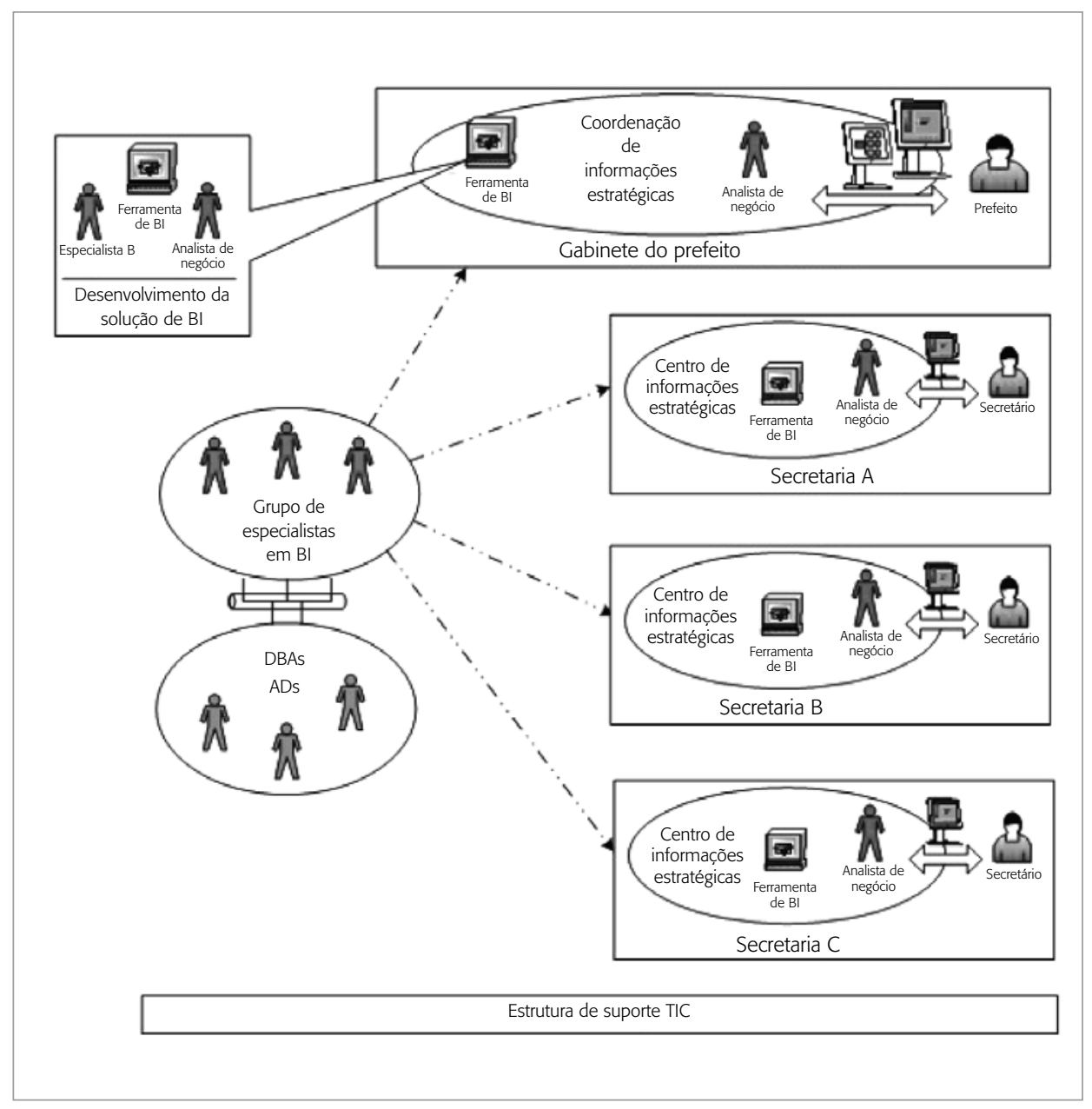




\section{Gestão dos processos internos (business process management - BPM)}

Tem como pré-requisito a existência de um planejamento estratégico municipal ou de, pelo menos, um planejamento estratégico interno da prefeitura. Partindo do planejamento estratégico municipal, com os objetivos e metas especificados, a gestão dos processos internos é elaborada com foco na gestão de processos ligados aos objetivos estratégicos definidos, gerando o modelo estratégico de processos.

A gestão dos processos internos com um foco estratégico viabiliza importantes vantagens para as administrações públicas municipais, pois a maioria dos processos existentes requer a participação, cooperação e comunicação de vários setores e/ou secretarias municipais, e o gestor público tem dificuldade para conhecer, monitorar e controlar esses processos estratégicos.

\section{Framework para implantação da BPM}

O modelo é baseado no framework elaborado pelo Business Process Management Group (BPMG), denominado 8 Omega, elaborado com base em experiências práticas de implantação da BPM e formatado para se adaptar a organizações de todos os tamanhos e possibilitar certa liberdade para a escolha do BPMG.

Utilizando esse framework é possível medir a maturidade dos processos de uma organização e avaliar onde a organização está agora e aonde quer chegar em relação à gestão de seus processos. Esse framework também define as fases e as respectivas atividades necessárias para implementação da BPM em organizações (BPMG, 2005).

Compondo o framework, existe uma matriz de maturidade dos processos que analisa nove categorias (comprometimento da alta administração, organização e estrutura, treinamento, indicadores de performance, funcionamento das equipes, ferramentas e técnicas, relacionamentos com stakeholders, integração dos sistemas de informação, credibilidade dos processos) correspondendo cada categoria a um nível de maturidade atual e de maturidade desejado, sendo que existem nove níveis de maturidade (desde 0 até o nível de maturidade máximo 8).

O 8 Omega define as fases e atividades para implementação do modelo estratégico de processos (modelo de gestão corporativa por processos) (BPMG, 2005). 


\section{Gestão corporativa por processos}

O modelo proposto de BPM, mapeando, monitorando e controlando os processos estatégicos, permitiria uma simbiose com o painel de bordo da estratégia (balanced scorecard - BSC). Então, o prefeito e secretários municipais teriam à sua disposição o acompanhamento da execução da estratégia municipal pelo BSC, com seus principais indicadores alimentados em tempo real pela BPM, conforme a figura 9 .

Gestão corporativa por processos

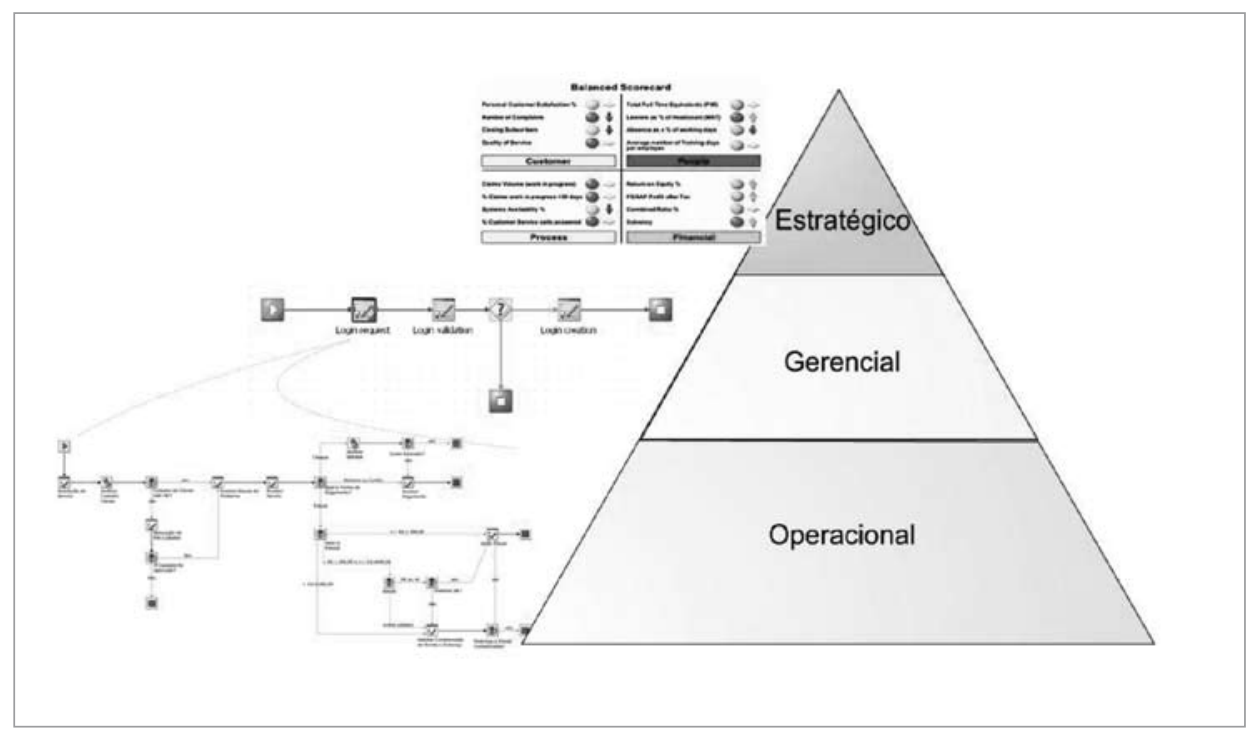

Para exemplificar, pode-se supor uma situação em que um indicador do BSC apresenta estado crítico. É possível visualizar todo o processo que gera esse indicador, localizando qual processo, ou parte do processo, que está ocasionando o problema. Uma vez localizado o processo problemático, ele pode ser remodelado e podem ser simulados diferentes cenários até que se encontre a melhor solução. O processo é então alterado e novas medições do seu desempenho permitem o monitoramento do sucesso ou fracasso no tratamento específico dele e seus impactos no plano geral. 


\section{Utilizando a BPM para interação com o cidadão}

Uma vez que os processos estratégicos estejam mapeados a BPM pode ser utilizada como uma nova forma de interação entre administração pública e cidadãos. Esses processos estratégicos mapeados podem ser disponibilizados aos cidadãos, permitindo que ele conheça de forma detalhada as ações estratégicas da prefeitura, com a definição de todas as atividades e responsabilidades envolvidas.

\section{Ambiente decisório (group decision support system - GDSS)}

O ambiente decisório segue os conceitos do group decision support system (GDSS), sendo essencialmente uma sala de reuniões para 16 participantes com recursos tecnológicos e de sistemas de informação para apoio à tomada de decisões em grupo (figura 10).

\section{Figura 10}

\section{Estrutura de ambiente decisório, baseado no GDSS}

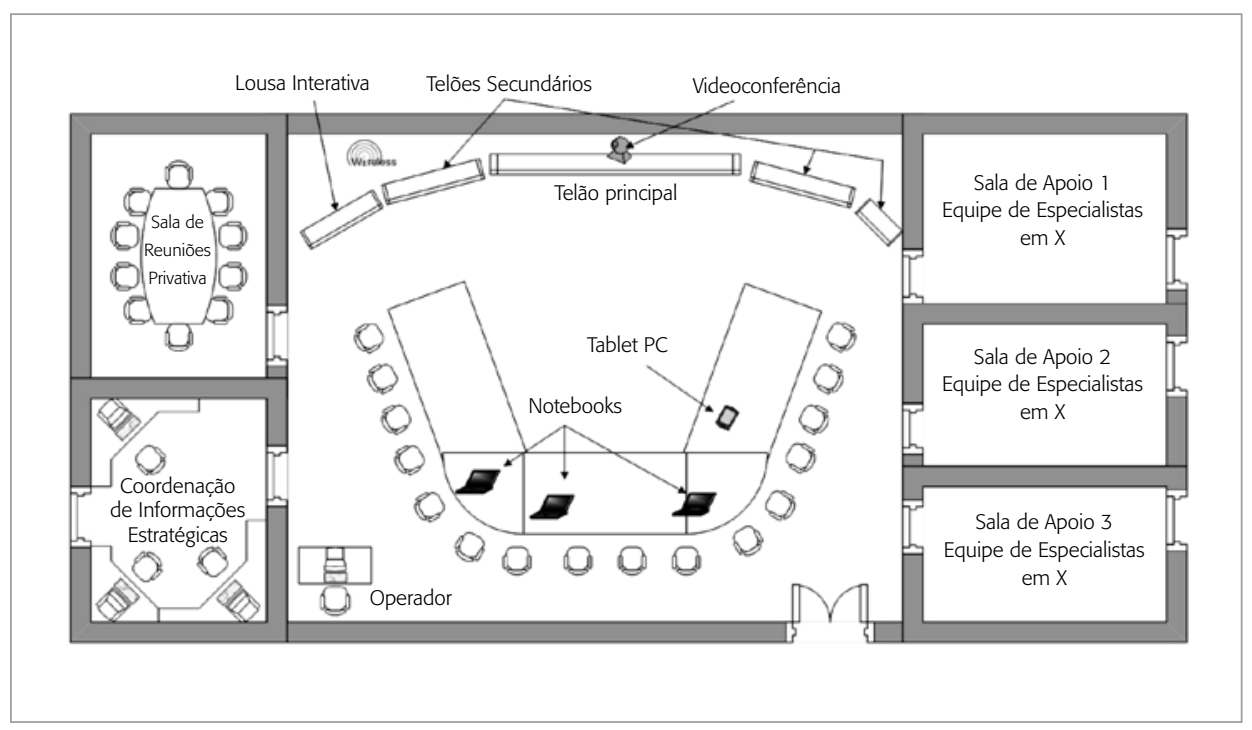

Na sala principal os participantes da reunião ficam dispostos em uma mesa formato de "U", tendo ainda uma mesa com equipamento específico para um operador dos recursos tecnológicos da reunião. Essa sala possui um telão principal para dar o foco da discussão e telões secundários para a 
exibição de suporte para as informações que estão sendo discutidas no telão principal.

O ambiente decisório possui ainda uma estrutura de apoio, composta por três salas de apoio, com equipes de especialistas conforme o tema que está sendo discutido. Esses grupos de especialistas podem ser relacionados a áreas técnicas de informática como por exemplo: analistas de negócio (auxiliando no mapeamento dos processos), técnicos na ferramenta de BPM (auxiliando na utilização das ferramentas de BPM), analista de sistemas (auxiliando na utilização de um sistema de informação transacional da organização). Esses grupos de especialistas também podem ser compostos por profissionais diretamente relacionados à área em discussão como saúde, educação, planejamento, urbanismo, segurança etc. Ou ainda serem formados grupos multidisciplinares, com representantes de diversos segmentos da sociedade. Essas equipes de especialista contam com recursos tecnológicos para o levantamento de informações objetivando apoiar o processo decisório da sala principal.

Para uma análise acadêmica, o ambiente decisório pode ser visualizado, como a integração de quatro diferentes módulos, conforme os recursos de sistemas de informação envolvidos: módulo de comunicação, módulo de informação, módulo de análise e módulo de simulação e agenda (figura 11).

O módulo de comunicação abrange videoconferência, conversas internas online (comunicador instantâneo) e a possibilidade de gravação de áudio e vídeo integrados às informações que estão em exibição nos telões.

O módulo de informação contempla a utilização dos sistemas transacionais utilizados pela organização e acesso às suas bases de dados, suporte a apresentações e o armazenamento das informações utilizadas e trabalhadas durante a reunião.

O principal módulo do ambiente decisório, o módulo de análise, compreende as ferramentas que possibilitam o monitoramento, integração, relacionamento e análise das informações. Aqui podem ser destacados o painel de bordo da estratégia (BSC), a inteligência do negócio (BI), a gestão dos processos internos (BPM) e a gestão de relacionamento com os cidadãos (CzRM). Também no módulo de análise pode existir um sistema para utilização interno ao ambiente decisório para priorização de demandas de informação para as demais equipes de apoio ou para o centro de informações estratégicas e um sistema de voto eletrônico com o objetivo de enriquecer as discussões. 


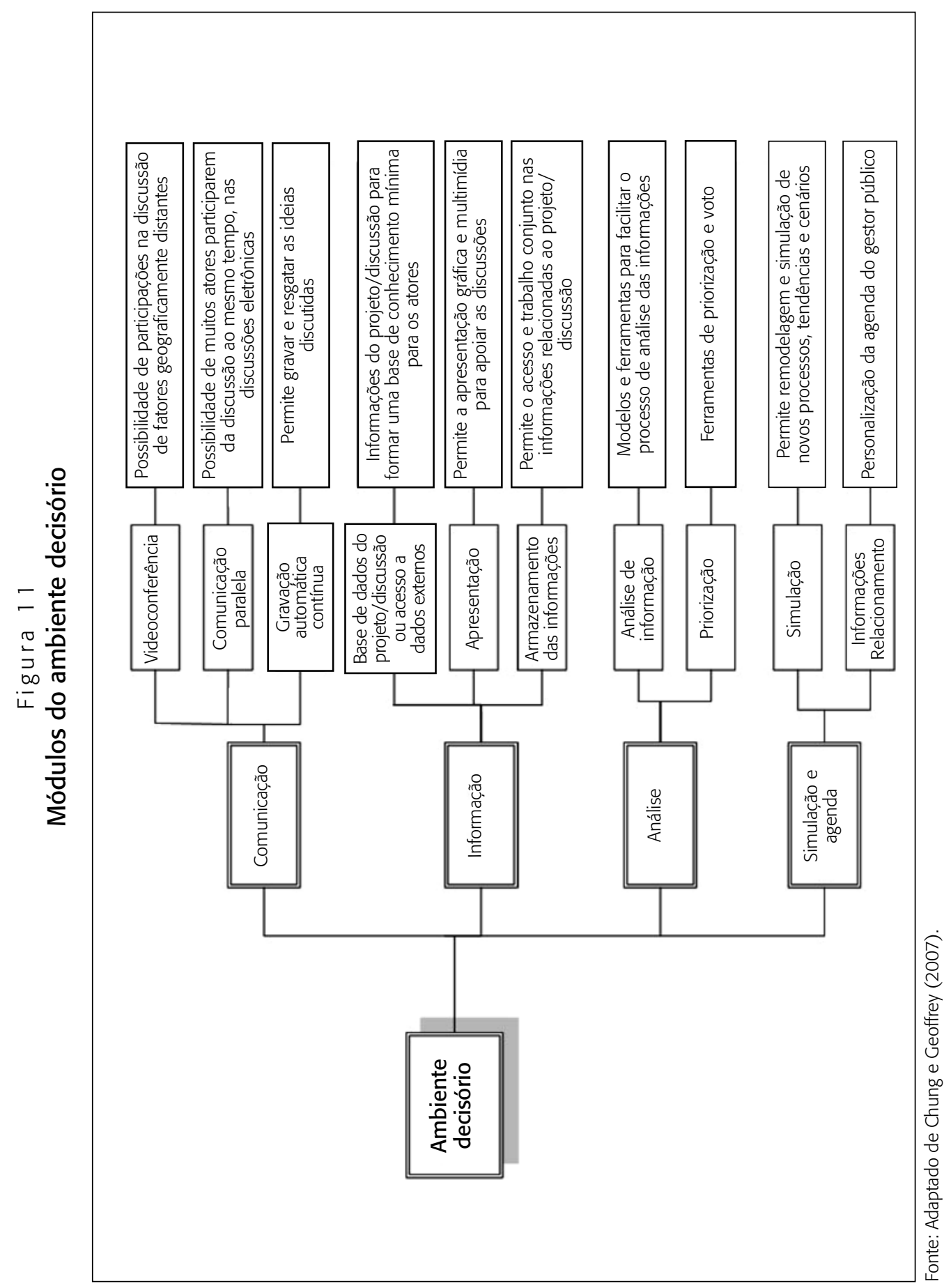




\section{Figura 12}

\section{Representação do ambiente decisório}

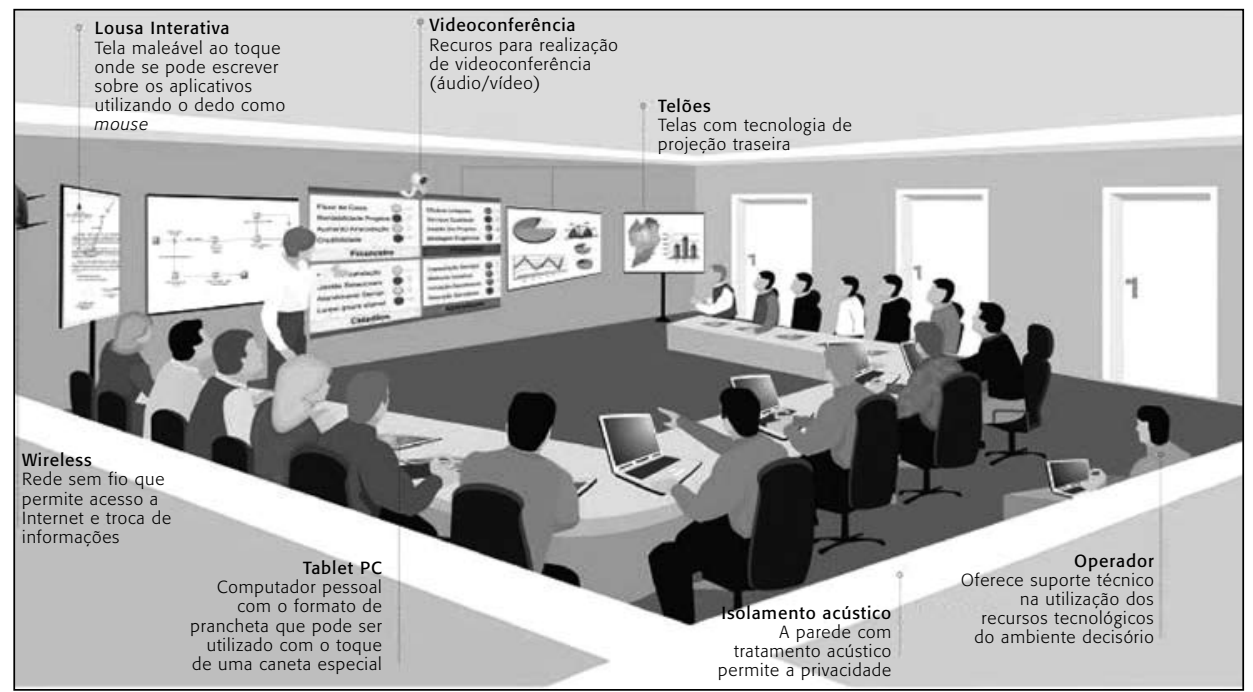

O módulo de simulação e agenda é representado principalmente pela gestão dos processos internos (BPM) com a simulação de novos processos e na interação com os cidadãos com a utilização de ferramentas de BPM. A agenda é a gestão de relacionamento com os cidadãos (CzRM) aplicada no apoio de informações para o gestor público, alinhada com sua agenda de participação em reuniões e eventos.

Nesse ambiente decisório pode ser observada a convergência dos demais elementos do modelo proposto (BSC, BI, CzRM e BPM), possibilitando aos administradores públicos municipais o acompanhamento e a gestão da performance governamental (ambiente decisório representado na figura 12).

\section{Metodologia da pesquisa}

Desde a fundamentação teórica até a proposição do modelo, essa pesquisa é identificada como bibliográfica exploratória. Já na fase de análise do modelo proposto, utiliza métodos e processos relativos a um estudo de caso.

Para a coleta de dados, utilizaram-se pesquisas bibliográficas e documentais, observações não participantes e entrevistas semiestruturadas. Quanto à abrangência da pesquisa, o estudo de caso restringiu-se à Prefeitura Municipal de Curitiba (PMC), representada por seus órgãos de administração direta e indireta, e pelo Instituto Curitiba de Informática (ICI), 
organização social responsável pela execução das políticas de tecnologia da informação em Curitiba.

As equipes que integraram esse processo de pesquisa pertencem às áreas de sistemas de informação, pesquisa e desenvolvimento e business intelligence, tanto do ICI quanto de outros órgãos da PMC. De analistas a gerentes, todos os integrantes de projetos relacionados ao modelo proposto contribuíram com a construção e avaliação dessa proposta.

A partir da definição do formato do modelo proposto, e com vistas para a realização do estudo de caso, foi preparado um protocolo de pesquisa com cinco constructos, cada qual relacionado a um dos elementos do modelo proposto.

Cada qual dos cinco constructos apresenta diversas variáveis e questões. Cada questão formulada foi avaliada em conformidade com unidades de medida preestabelecidas: existência, aderência ao modelo e resultados.

\section{Proposta e avaliação do modelo para a gestão governamental}

As tabelas dos diferentes constructos são simplificadamente apresentadas neste artigo. Os constructos coincidem com os elementos do modelo proposto, os quais foram baseados em análises realizadas na gestão da prefeitura de Curitiba.

\section{Painel de bordo da estratégia (balanced scorecard - BSC)}

Neste estudo de painel de bordo foram pesquisadas as ações realizadas pelo Instituto Municipal de Administração Pública (Imap) em conformidade com as diretrizes do plano de governo do prefeito. Existe também um sistema de informação desenvolvido exclusivamente para estruturação e acompanhamento das ações relacionadas à estratégia de governo, o Sistema de Acompanhamento das Ações de Governo (Saga).

\section{Quadro 1}

Análise do constructo painel de bordo da estratégia (BSC)

\begin{tabular}{|ll|}
\hline Variável & Unidade de medida \\
\hline $\begin{array}{l}\text { Pré-requisitos } \\
\text { (planejamento estratégico) }\end{array}$ & Existência: o plano de governo assume o papel de planejamento \\
& Aderatégico. \\
& utilizado pela administração municipal, mas as perspectivas utilizadas são \\
& totalmente diferentes das perspectivas do modelo proposto. \\
\hline
\end{tabular}




\begin{tabular}{|c|c|}
\hline Variável & Unidade de medida \\
\hline Financeira & Existência: não existe a perspectiva financeira. \\
\hline Cidadãos & Existência: não existe a perspectiva cidadãos. \\
\hline Processos internos & Existência: não existe a perspectiva processos internos. \\
\hline $\begin{array}{l}\text { Aprendizagem e } \\
\text { crescimento }\end{array}$ & Existência: não existe a perspectiva aprendizado e crescimento. \\
\hline \multirow[t]{2}{*}{ Tecnologia } & $\begin{array}{l}\text { Existência: sim. Foi desenvolvido um sistema de informação para suportar } \\
\text { o modelo de gestão da estratégia adotado pela administração municipal. }\end{array}$ \\
\hline & $\begin{array}{l}\text { Aderência ao modelo: o sistema apresenta algumas características } \\
\text { expostas no modelo proposto, mas ainda falta a integração com os } \\
\text { demais sistemas da prefeitura. }\end{array}$ \\
\hline$\Rightarrow$ & $\begin{array}{l}\text { Resultados: } \\
\text { V estruturação e explicitação da estratégia; } \\
\text { v facilidade da integração com outros planos da prefeitura; } \\
\text { v acompanhamento da execução da estratégia, pelos gestores públicos e } \\
\text { pela população. }\end{array}$ \\
\hline
\end{tabular}

\section{Gestão de relacionamento com os cidadãos (citizen relationship management - CzRM)}

No tocante ao relacionamento com o cidadão, a PMC vem utilizando a Central 156, já fortemente enraizada na cultura de trabalho municipal; a Central de Relacionamento da PMC e o Sistema de Identificação do Cidadão, todos sob gestão do Instituto Curitiba de Informática (ICI).

\section{Quadro 2}

Análise do constructo gestão do relacionamento com os cidadãos (CzRM)

\begin{tabular}{|c|c|}
\hline Variável & Unidade de medida \\
\hline \multirow[t]{2}{*}{ Estrutura } & Existência: sim, já bem consolidado no dia a dia da prefeitura. \\
\hline & $\begin{array}{l}\text { Aderência ao modelo: similar ao modelo. Diferença que um contact } \\
\text { center agrupa as funções, que conforme o modelo estariam divididas em } \\
\text { dois contact centers. }\end{array}$ \\
\hline \multirow[t]{2}{*}{ Tecnologia } & $\begin{array}{l}\text { Existência: sim. Apesar da integração de todos os sistemas por um } \\
\text { cadastro único de cidadãos ainda não estar finalizado. }\end{array}$ \\
\hline & Aderência ao modelo: utilização de tecnologias similares às do modelo. \\
\hline \multirow[t]{2}{*}{ Pessoas } & $\begin{array}{l}\text { Existência: o estudo de caso mostrou a preocupação com a qualificação } \\
\text { da equipe envolvida. }\end{array}$ \\
\hline & Aderência ao modelo: o modelo não aborda as pessoas envolvidas. \\
\hline
\end{tabular}




\begin{tabular}{|ll|}
\hline Variável & Unidade de medida \\
\hline Conhecer os cidadãos & Existência: as informaç̃es dos cidadãos são efetivamente utilizadas para \\
& o planejamento e a gestão urbana. \\
& Resultados: \\
& v serviço de atendimento de demandas consolidado e com boa aceitação \\
& pela população; \\
& $\checkmark$ levantamento e monitoramento dos anseios, necessidades, opiniões e \\
& níveis de satisfação da população; \\
& relacionamento ativo com a realização de convites e divulgações \\
& "personalizados". \\
\hline
\end{tabular}

\section{Inteligência do negócio (business intelligence - BI)}

Com relação à inteligência do negócio, foi estudada a implantação do BI na PMC, projeto executado pelo Instituto Curitiba de Informática (ICI), como projeto Sala de Situação, de acordo com o contrato de gestão firmado entre PMC e ICI em 2006.

$$
\text { Quadro } 3
$$

Análise do constructo inteligência do negócio (BI)

\begin{tabular}{|ll|}
\hline Variável & Unidade de medida \\
\hline Estrutura & Existência: sim, já utilizado por várias secretarias, mas não em todas as \\
& secretarias. \\
& Aderência ao modelo: bem próximo ao modelo. Diferenças principais \\
& nas nomenclaturas e ainda sem uma "coordenação de informações \\
& estratégicas". \\
Tecnologia & Aderência ao modelo: mesma tecnologia. \\
Pessoas & Aderência ao modelo: mesmos papéis, com a necessidade de inclusão \\
& no modelo, do analista de sistemas. \\
& Resultados: \\
& $\mathbf{v}$ levantamento de falhas, possibilitando a diminuição de custos; \\
& $\mathbf{v}$ geração de informações oportunas e personalizadas; \\
& \\
&
\end{tabular}

\section{Gestão dos processos internos (business process management - BPM)}

Nenhuma secretaria ou órgão municipal vem utilizando a BPM. O ICI, todavia, está implementando internamente soluções de BPM. No momento estão sendo feitos os testes iniciais e o alinhamento ao planejamento estratégico do 
instituto. Uma vez consolidada, a utilização da ferramenta será incentivada em toda a PMC.

Quadro 4
Análise do constructo gestão dos processos internos (BPM)

\begin{tabular}{|c|c|}
\hline Variável & Unidade de medida \\
\hline \multirow[t]{2}{*}{ Estrutura } & $\begin{array}{l}\text { Existência: não. A BPM não é utilizada nos órgãos diretos da administração } \\
\text { pública estudada. O estudo de caso foi realizado na organização social } \\
\text { responsável pela gestão da TI no município (implantação ainda em fase } \\
\text { inicial). }\end{array}$ \\
\hline & $\begin{array}{l}\text { Aderência ao modelo: o caso estudado (interno do ICI) é similar ao } \\
\text { modelo. }\end{array}$ \\
\hline Tecnologia & $\begin{array}{l}\text { Aderência ao modelo: utilização das mesmas tecnologias abordadas no } \\
\text { modelo proposto. }\end{array}$ \\
\hline Interação com os cidadãos & $\begin{array}{l}\text { Existência: não existe nenhuma previsão da interação com o cidadão } \\
\text { diretamente pela BPM. }\end{array}$ \\
\hline$\Rightarrow$ & $\begin{array}{l}\text { Resultados: } \\
\text { - mapeamento dos processos; } \\
\text { definição de regras e procedimentos; } \\
\text { - identificação dos perfis e recursos envolvidos em cada etapa do } \\
\text { processo; } \\
\text { alinhamento da estratégia com os processos e coleta automática de } \\
\text { indicadores; } \\
\text { monitoração online dos processos. }\end{array}$ \\
\hline
\end{tabular}

\section{Ambiente decisório (group decision support system - GDSS)}

O projeto desenvolvido pelo ICI, denominado Centro Integrado de Informações Estratégicas (contemplando em seu escopo a sala de situação) consiste em um ambiente destinado ao apoio à tomada de decisões em grupo, sustentado por ferramentas que permitem o monitoramento dos serviços prestados à comunidade e o levantamento e análise de informações.

A PMC vem utilizando a sala de situação (que usa os conceitos de GDSS) como um centro de estudo e soluções para a atividade pública municipal. Diversas secretarias realizam suas reuniões estratégicas nesse ambiente, fazendo uso das tecnologias e informações que ela proporciona.

Em nota publicada na Folha de S.Paulo, Melchiades Filho (2008) expõe:

Mas foi na gestão do tucano Beto Richa, em 2005, que surgiu a maior novidade: uma sala de situação, com telões e computadores. Nela, pode-se estudar as demandas declaradas (reclamações) e consumadas (atendimentos) dos curi- 
tibanos, recortá-las por região e até mesmo individualizá-las. Em tese, basta clicar em um endereço para descobrir a relação de seus moradores com o poder público. Imagine só o potencial de telemarketing.

Os números incríveis de Richa no último Datafolha ( $72 \%$ de intenção de voto) no mínimo guardam relação com esse jeito "online" de governar - que, ressalte-se, dá ao Executivo a possibilidade de prescindir de um meio-campo (imprensa, associações de bairro, vereadores) e fazer ligação direta com o eleitor.

Em outra nota publicada, Ribeiro (2008) destaca o seguinte:

Richa tratou de tornar-se um fazedor de obras, audiências públicas (mais de 200 ao longo dos quatro anos) e ouvir o que a população queria. Para isso também contou com o serviço de atendimento instalado no Instituto Curitiba de Informática (ICI), com capacidade para traçar o perfil da população em minúcias nas várias regiões da capital e elencar os seus problemas. Esse fato fez com que a aprovação de sua administração ultrapasse a marca de $80 \%$ segundo os principais institutos de pesquisa (...).

\section{Quadro 5}

\section{Análise do constructo ambiente decisório}

\begin{tabular}{|c|c|}
\hline Variável & Unidade de medida \\
\hline \multirow[t]{2}{*}{$\begin{array}{l}\text { Integração } \\
\text { estratégica }\end{array}$} & $\begin{array}{l}\text { Existência: utilização do Centro Integrado de Informações Estratégicas (tendo em } \\
\text { seu escopo a sala de situação). }\end{array}$ \\
\hline & $\begin{array}{l}\text { Aderência ao modelo: utilização da BI e da CzRM. O BSC está em fases iniciais } \\
\text { de utilização. Ainda sem previsão da utilização da BPM na PMC. Destaque para a } \\
\text { utilização ativa de geoprocessamento (item não contemplado no modelo). }\end{array}$ \\
\hline \multirow[t]{2}{*}{ Estrutura } & Existência: sim. \\
\hline & $\begin{array}{l}\text { Aderência ao modelo: similar ao modelo proposto. Diferenças nas nomenclaturas e } \\
\text { no número máximo de participantes da reunião. }\end{array}$ \\
\hline Tecnologia & $\begin{array}{l}\text { Aderência ao modelo: similares ao do modelo proposto. Mas ainda não há } \\
\text { previsão da utilização de tecnologias para o suporte à BPM diretamente na PMC. }\end{array}$ \\
\hline$\Rightarrow$ & $\begin{array}{l}\text { Resultado } \\
\text { O Centro Integrado de Informações Estratégicas é apontado como um dos indutores } \\
\text { para os elevados índices de aprovação da população em relação à atual gestão } \\
\text { municipal. }\end{array}$ \\
\hline
\end{tabular}

\section{Conclusão}

Com o objetivo de ser uma efetiva ferramenta para o gestor público, o modelo de gestão governamental aqui proposto concerne à otimização da utilização 
dos recursos e do favorecimento do acesso dos cidadãos aos serviços públicos. Esse modelo é focado no alinhamento do planejamento à execução estratégica, no apoio à tomada de decisão, no controle sobre os processos administrativos e na gestão dos relacionamentos com os cidadãos.

Os resultados obtidos com o estudo de caso, por constructo do modelo proposto, são descritos a seguir:

v painel de bordo da estratégia (balanced scorecard - BSC) — gestão e monitoramento do planejamento estratégico;

v inteligência do negócio (business intelligence - BI) - informações estratégicas, consistentes e combinadas, que sustentarão o processo decisório;

- gestão do relacionamento com os cidadãos (customer relationship management - CzRM) - estrutura municipal utilizando contact centers e bases cadastrais integradas dos cidadãos para solucionar problemas e reivindicações feitas pelos cidadãos;

- gestão dos processos internos (business process management - BPM) - mapeamento, alinhamento e controle dos processos administrativos internos da organização;

v ambiente decisório (group decision support system - GDSS) — indutor para uma administração pública efetiva e alinhada com os anseios da população.

A viabilidade da implantação desse modelo em diversos municípios, não obstante suas singularidades estruturais e orçamentárias, reside na flexibilidade e modulação proporcionada pelos constructos. Da forma como foi projetado, o modelo permite o atendimento das necessidades e prioridades específicas de cada gestão. Além disso, as diversas customizações empregadas podem estar baseadas em conceitos da iniciativa privada - que, a propósito, originaram o modelo proposto. A competitividade de mercado impele as organizações a práticas sempre mais efetivas, que devem ser aproveitadas pela iniciativa pública.

Contudo, é importante destacar que o sucesso do modelo proposto está condicionado à utilização consciente e responsável dessas informações pelos gestores públicos. Os cidadãos só desfrutarão dos benefícios de uma gestão efetivamente estratégica quando o conhecimento resultante de todo esse processo for, de fato, utilizado em seu proveito. O usufruto dessas informações passa ainda por uma mudança cultural em toda a estrutura da administração pública municipal. Embora sejam os níveis estratégicos e decisórios que fazem uso deles, os sistemas de informações são alimentados 
pelos níveis gerenciais e operacionais, cujo comprometimento impacta diretamente no êxito do processo.

Como contribuição para a entidade pesquisada, este artigo deu sua contribuição ao construir esse modelo de gestão governamental, visando a uma gestão mais efetiva dos recursos públicos. A proposta, por seu caráter modular e flexível, permite que o gestor público a adapte conforme suas expectativas, seja simplificando a proposição original, seja inserindo novos modelos de gestão e tecnologias. Para outros municípios, a contribuição foi trazer conceitos de gestão da iniciativa privada para a pública, fomentando o estudo, a adaptação e a utilização de modelos que certamente contribuirão para tornar a administração pública mais efetiva. Para a academia, a combinação de diferentes modelos e conceitos de gestão com propósitos distintos, mas complementares, foi o destaque principal.

Foi fator limitador para a execução deste artigo o fato de o estudo de caso não analisar o modelo proposto aplicado de forma integral, mas dividido por constructos.

Outras pesquisas podem ser realizadas a partir deste artigo. É possível aperfeiçoar o modelo proposto, ampliar sua abrangência, acrescentar outros modelos e conceitos, expandir a quantidade de municípios estudados e analisar evolutivamente os resultados obtidos a partir da implantação do modelo proposto.

\section{Referências}

BARBIERI, C. BI - business intelligence: modelagem \& tecnologia. Rio de Janeiro: Axcel Books, 2001.

BOTH, E.; DILL S. Business intelligence aplicado em saúde pública. In: CONGRESSO SUL CATARINENSE DE COMPUTAÇÃO, 1., 2005, Criciúma. Anais eletrônicos... Criciúma: Sulcomp, 2005. Disponível em: <www.dcc.unesc.net/sulcomp/05/ Art101SulComp2005.pdf>. Acesso em: 20 jul. 2006.

BPMG (Business Process Management Group). 8 Omega Orca: Organization Readlines \& Competence Assessment Guide. Boston, 2005. Disponível em: <www.bpmg. org >. Acesso em: $28 \mathrm{dez} .2006$.

BRETZKE, Miriam. Marketing de relacionamento e competição em tempo real com CRM. São Paulo: Atlas, 2000.

CHUNG, J.; GEOFFREY, Q. Using group decision support systems to support value management. Disponível em: <http://home.bre.polyu.edu.hk/ bsjacky/gdss/ L4.htm>. Acesso em: 18 jul. 2007. 
CUNHA, M. Portal de serviços públicos e de informação ao cidadão: estudo de casos no Brasil. 2000. 172f. Tese (Doutorado em Administração) — Faculdade de Economia e Administração, Universidade de São Paulo, São Paulo.

DAVENPORT, T.; PRUSAK, L. Ecologia da informação: por que só a tecnologia não basta para o sucesso na era da informação. São Paulo: Futura, 2000.

DUTRA, A. A importância de conhecer os processos de negócio. Agência Estado. São Paulo, fev. 2004. Disponível em: <www.aesetorial.com.br/tecnologia/ artigos/2004/fev/16/442.htm>. Acesso em: 5 jan. 2007.

FREY, K. Governança urbana e participação pública. In: ENCONTRO ANUAL DA ANPAD, 28., 2004, Curitiba. Anais... Curitiba: Anpad, 2004.

GHELMAN, S. Adaptando o balanced scorecard aos preceitos da nova gestão pública. 2006. 86f. Dissertação (Mestrado em Sistema de Gestão pela Qualidade Total) - Universidade Federal Fluminense, Niterói.

GRAHAM, C. Para administrar a organização pública. Rio de Janeiro: Jorge Zahar, 1994.

GRIGORI, D. et al. Business process intelligence. Computers in Industry, v. 53, n. 3, p. 321-343, Apr. 2004. Disponível em: <www.prism.uvsq.fr/ grig/These/ci.pdf>. Acesso em: 28 dez. 2006.

HERRERO, E. Balanced scorecard e a gestão estratégica: uma abordagem prática. Rio de Janeiro: Elsevier, 2005.

JESTON, J.; NELIS; J. Business process management: practical guidelines to successful implementations. Burlington: Elsevier, 2006.

KAPLAN, R.; NORTON, D. Kaplan e Norton na prática. Rio de Janeiro: Elsevier. 2004.

LABP3. Rede de tecnologia de processos. Disponível em: <www.labp3.com.br>. Acesso em: 20 dez. 2006.

LAPPEENRANTA UNIVERSITY OF TECHNOLOGY. Department of Industrial Management. GDSS Laboratory. Disponível em: <www.lut.fi/tuta/en/research/gdss. html>. Acesso em: 18 jul. 2007.

MELCHIADES FILHO. Piá curitibano. Folha de S.Paulo, São Paulo, 26 jul. 2008. Disponível em: <www1.folha.uol.com.br/fsp/opiniao/fz2607200804.htm>. Acesso em: 6 out. 2008.

MONTEIRO, M. H. Por que é o BPM — business process management - uma das apostas para a mudança na administração pública? Revista Informação e Informática, n. 28, p. 30-34. mar. 2004. Disponível em: <www.inst-informatica.pt/v20/ documentos/p_rev/rev_28/Artigo4.pdf > . Acesso em: 8 jan. 2007. 
NIVEN, P. Balanced scorecard passo a passo: elevando o desempenho e mantendo resultados. Rio de Janeiro: Qualitymark, 2005.

NUNAMAKER, J. et al. Lessons from a dozen years of group support systems research: a discussion of lab and field findings. Journal of Management Information Systems, v. 13, n. 3, p. 163-207, 1997. Disponível em: <www.cmi.arizona.edu/ pubs/Nunamaker-JMIS-Lessons_learned.pdf>. Acesso em: 18 jul. 2007.

OLVE, N.; ROY, J.; WETTER, M. Condutores da performance: um guia prático para uso do balanced scorecard. Rio de Janeiro: Qualitymark, 2001.

PFEIFFER, P. Planejamento estratégico municipal no Brasil: uma nova abordagem. Brasília: Enap, 2000.

PORTUGAL. Ministério das Finanças e Administração Pública. Sistema integrado de avaliação do desempenho da administração pública: preâmbulo da Lei n. 23/2004. Lisboa, 2004. Disponível em: <www.min-financas.pt/legislacao/RefAP.asp>. Acesso em: 20 set. 2007.

QLIKVIEW. Manual de referência: instalação, scripts e macros. Florianópolis, 2004.

. Tutorial. Florianópolis, 2005.

REZENDE, D. A. Planejamento de informações públicas municipais: guia para planejar sistemas de informação, informática e governo eletrônico nas prefeituras e cidades. São Paulo: Atlas, 2005.

; CASTOR, B. J. V. Planejamento estratégico municipal: empreendedorismo participativo nas cidades, prefeituras e organizações públicas. 2. ed. Rio de Janeiro: Brasport: 2006.

RIBEIRO, Pedro. Trajetória. Documento Reservado, Curitiba, 6 out. 2008. Disponível em: <www.documentoreservado.com.br>. Acesso em: 6 out. 2008.

SPRAGUE, R.; WATSON, H. Sistemas de apoio à decisão: colocando a teoria em prática. Rio de Janeiro: Campus, 1991.

SWIFT, R. CRM - customer relationship management: o revolucionário marketing de relacionamento com os clientes. Rio de Janeiro: Campus, 2001.

UNIVERSITY OF ARIZONA. Center for the management of information. Executive decision center. Disponível em: <www.cmi.arizona.edu/go.spy?xml=edc.xml>. Acesso em: 18 jul. 2007.

ZENONE, L. Customer relationship management (CRM) conceitos e estratégias: mudando a estratégia sem comprometer o negócio. São Paulo: Atlas, 2001. 